\title{
Mechanisms of Chronic Heart Failure Development in End-Stage Renal Disease Patients on Chronic Hemodialysis
}

\author{
J. MALÍK ${ }^{1}$, V. TUKA ${ }^{1}$, M. MOKREJŠOVÁ ${ }^{2}$, R. HOLAJ ${ }^{1}$, V. TESA $\check{R}^{2}$ \\ ${ }^{1}$ Third Department of Internal Medicine and ${ }^{2}$ Department of Nephrology, General University \\ Hospital, First School of Medicine, Charles University, Prague, Czech Republic
}

Received May 19, 2008

Accepted September 15, 2008

On-line November 4, 2008

\begin{abstract}
Summary
More than $50 \%$ of end-stage renal disease (ESRD) patients treated by chronic hemodialysis die from cardiovascular diseases, including congestive heart failure (CHF). The incidence of CHF is rising in both general and ESRD population. However, the mechanisms, which lead to the development of CHF in dialyzed patients, differ considerably. First, there are several factors leading to increase of the left ventricular afterload: volume overload between dialyses, hypertension, increased arterial stiffness, anemia, vascular access flow (arteriovenous fistula) and sympathetic activation. Second, hypertension, left ventricular hypertrophy, anemia and frequently present coronary artery disease worsen myocardial oxygenation. The combination of these factors explains the high incidence of CHF in dialyzed patients and their roles are reviewed in this article.
\end{abstract}

\section{Key words}

Heart failure • Dialysis • Volume overload • Pressure overload

\section{Corresponding author}

Jan Malik, MD, PhD, Third Department of Internal Medicine, General University Hospital, U nemocnice 1, 12808 Prague, Czech Republic. Fax: +420224923 852. E-mail: malik.jan@vfn.cz

\section{Prevalence, mortality, morbidity}

More than $50 \%$ of end-stage renal disease (ESRD) subjects treated by chronic hemodialysis die from cardiovascular diseases (Collins 2003). Congestive heart failure $(\mathrm{CHF})$ is present in more than one-third of new dialysis patients (Stack and Bloembergen 2001) with an incidence of 71/1000 person-years. This figure is substantially greater than the incidence of acute coronary syndromes in ESRD patients (29/1000 person-years in US Renal Data System (USRDS) Morbidity and Mortality Study Wave 2) (Trespalacios et al. 2003). CHF contributes significantly to mortality and morbidity and also worsens the quality of life. For instance, the median overall survival of ESRD patients with CHF is reported to be 36 months compared with 62 months in patients without CHF (Harnett et al. 1995). Fewer than $15 \%$ of dialysis patients are alive 3 years after hospitalization for CHF (Trespalacios et al. 2003).

By definition, CHF is a state in which the heart is unable to pump blood at a rate appropriate to the requirements of the metabolizing tissues or can do so only at an elevated filling pressure (Zipes et al. 2005). $\mathrm{CHF}$ in ESRD patients differs from CHF states in subjects with preserved renal function by several factors. Interdialytic volume overload and vascular access flow are specific only for ESRD. Therefore, hemodialysis also contributes per se to the development of CHF. During continuous worsening of chronic kidney disease, nephrogenic hypertension develops. This is the source of pressure overload, especially in patients with inadequate hypertension control. Most important mechanisms of $\mathrm{CHF}$ in ESRD patients treated by hemodialysis are discussed below. We did not include the problems associated with peritoneal dialysis nor kidney transplantation to keep this review more transparent. 
Increased left ventricular mass (hypertrophy) (LVH) is the most frequent cardiac abnormality diagnosed in patients starting hemodialysis (present in about 80 \%) (Foley et al. 1995, Herzog et al. 1998). LVH is an independent and strong risk factor for cardiovascular morbidity and mortality in both normal population (Levy et al. 1990) and in ESRD patients (Silberberg 1989). In the latter population, LVH is principally due to an increased demand in the left ventricular minute work resulting from volume/flow and pressure overload (Meeus et al.1989). Two forms of the left ventricular hypertrophy - eccentric and concentric could be present and are relatively equivalent in prevalence in dialysis population. Eccentric hypertrophy results from volume overload leading to cardiac myocyte drop-out: there is myocyte to arteriolar capillary mismatch. Concentric hypertrophy is typically the result of hypertension and increased afterload and is exacerbated by anemia, hyperparathyreoidism, and high angiotensin II concentrations. In experimental renal failure, LVH was associated with reduced capillary density and subsequent interstitial fibrosis (Mall et al. 1990, Amann et al. 1990). The latter is probably a reason of diastolic and later also systolic dysfunction of the left ventricle present in LVH. While in general population hypertension is the most frequent cause of the left ventricle hypertrophy, in ESRD patients, the correlation between left ventricle mass and blood pressure is weak. Experimental and clinical studies have shown that hypertrophy develops even in normotensive ESRD subjects (London et al. 1987).

Schematically, factors contributing to the development of CHF include those increasing preload and decreasing the myocardial perfusion or oxygenation of the left ventricle (Table 1). Left ventricular afterload is increased by some and decreased by other mechanisms (Fig. 1).

\section{Mechanisms of CHF}

\section{Volume overload between dialyses}

Most subjects with ESRD have insufficiently low or even no diuresis, which leads to water retention. Excessive water is removed during dialysis sessions by ultrafiltration. Nevertheless, dialysis is usually performed only 2-3 times per week and body water accumulates and fluctuates between the dialysis sessions. This fluctuation plays a role in the development of the left ventricular hypertrophy, which in turn predisposes to CHF (London
Table 1. Factors leading to the increase of preload and to the worsening of myocardial oxygen supply.

\begin{tabular}{ll}
\hline \multirow{4}{*}{ TPreload } & Interdialytic volume overload \\
& Anemia \\
& Vascular access flow \\
& Inflammation \\
\hline \multirow{4}{*}{ Cardiac oxygen supply } & $\begin{array}{l}\text { Anemia } \\
\text { Hypertension } \\
\\
\end{array}$ \\
\hline
\end{tabular}

2003a,b). The ultrafiltration rate is targeted to reach so called dry weight of the patient. There are several methods of dry weight calculation. To simplify, dry weight is the minimal tolerated weight - without clinical signs of dehydration. Inappropriate calculation of the dry weight leads to chronic volume overload (Charra 2007).

Overhydration between the dialyses contributes to the pathogenesis of LVH in ESRD by its effects on blood pressure control and also by induction of volume overload (London 2003a,b). The internal dimensions of the left ventricle, stroke volume, and end-diastolic pressure are directly related to circulating blood volume (Chaignon et al. 1981). Body fluid volume reduction during dialysis sessions induces a decrease in left ventricle diameter and cardiac output, and there is a direct correlation between interdialytic body weight changes and LV mass, as well as stroke volume (Harnett 1993). LV mass correlates with the concentrations of atrial natriuretic peptides, which are influenced by extracellular fluid volume (Zoccalli et al. 2001). Regression of the left ventricular dimensions and LVH can be achieved by ultrafiltration and reduced salt intake in hemodialysis patients (Ozkahya et al. 1998). Indeed, patients treated by daily dialysis have lower and steadier levels of brain natriuretic peptide (BNP), the marker of heart failure and overhydration (Odar-Cederlof et al. 2006). A similar LVH reduction was associated with better blood pressure control, decrease in extracellular fluid volume, and with lower volume fluctuation in patients on daily dialysis (Fagugli et al. 2001).

\section{Anemia}

Anemia is a frequent condition even in milder stages of chronic renal disease, mainly due to decreased synthesis of erythropoietin. Non-hemodynamic mechanisms of body adaptation to anemia include 


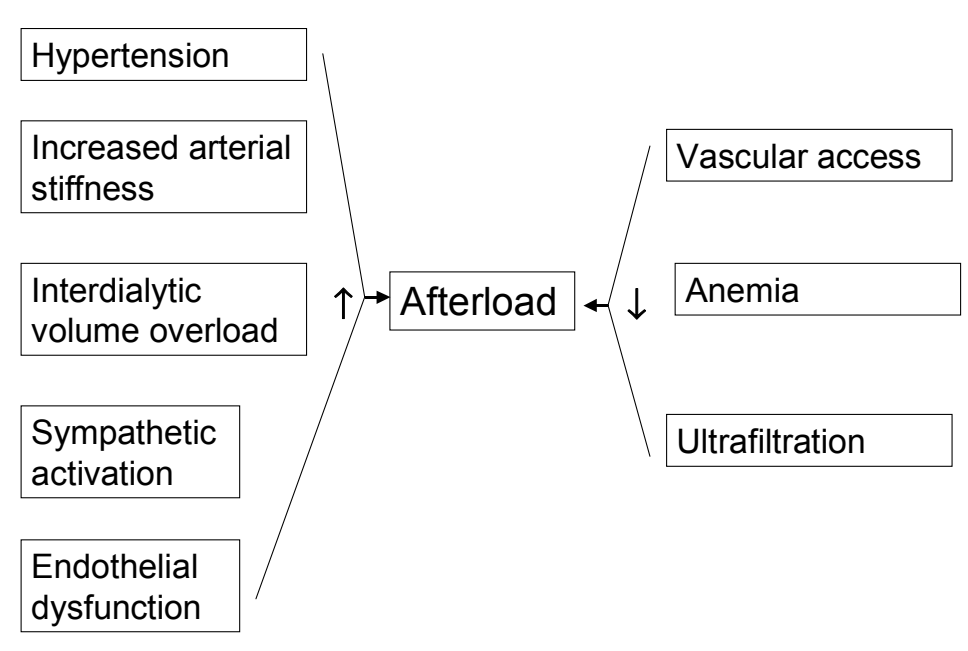

Fig 1. Factors influencing left ventricle afterload. Afterload increasing mechanisms are listed in the left side of the figure, afterload lowering factors on the right side. increased oxygen extraction in tissues, mediated by increased 2,3-diphosphoglycerate levels. Mechanisms of hemodynamic compensation of anemia are complex: 1) reduced afterload due to a decrease in systemic vascular resistance, 2) increased preload due to an increase in venous return, and 3) increased left ventricular function attributed to increased sympathetic activity and inotropic factors. Increased left ventricular performance can result from an increased preload (Frank-Starling mechanism) and from changes in inotropic state in relation to high sympathetic activity or inotropic factors (Muller et al. 1991). In chronic anemia, typical for ESRD, long-lasting flow/volume overload and increased cardiac work lead to progressive cardiac enlargement and to the left ventricular hypertrophy (Parfrey et al. 1991). The alterations in cardiac function are accompanied by simultaneous remodeling of the large conduit arteries (London et al. 1996). Indeed, in dialysis patients, anemia is associated with LVH, left ventricular dilatation, congestive heart failure, increased hospitalization rate, and increased mortality (Foley et al. 1996a,b, Ma et al. 1999, Madore et al. 1997).

In patients on dialysis, treatment of anemia with erythropoietin alters both the function and the structure of the left ventricle. It decreases the stroke volume and heart rate, and decreases the cardiac output and left ventricular work (Fellner et al. 1993). Older studies showed optimistic data of mortality risk decrease (Moecks 2000). Recent studies compared the lower and higher target hemoglobin values (10.5-11.5 g/dl and 13.0-13.5 g/dl, respectively). They failed to show any benefit of higher target hemoglobin value except for better quality of life (Drueke et al. 2006, Singh et al. 2006). In a metaanalysis, patients in the higher target value group had higher mortality (Phrammintikul et al. 2007). It was speculatively explained by increased rate of thromboses, including infarctions as a result of both higher hematocrit, and by some direct effects of erythropoietin favoring inflammatory states.

\section{Hypertension and arterial wall stiffness}

Chronic kidney disease could be both the reason and the result of hypertension. This is probably a source of the very high hypertension prevalence in ESRD subjects. For example, in our previous study, more than $70 \%$ of 258 subjects coming for vascular access examination into our department from the whole country suffered from hypertension (Malík et al. 2007). In nonESRD patients, several studies have repeatedly confirmed that the treatment of high blood pressure decreases both cardiac and particular cerebrovascular events in patients with diabetes (Schrier et al. 2002) as well as in those without diabetes (Hansson et al. 1999). Similarly, decreasing blood pressure has been shown to prevent progression of renal disease (Bakris et al. 2000). A new light was brought by a series of subsequent studies, which were meta-analyzed by the project "INDIANA" (Boutitie et al. 2002). It has been shown that lowering diastolic blood pressure is protective until a certain level and then the risk of all-cause mortality rises again: J-shaped curve. The authors have revealed a J-point at a diastolic blood pressure of $84 \mathrm{mmHg}$. There are several possible explanations of this phenomenon and two of them seem to be particularly important. First, subjects with low blood pressure suffer probably from more severe cardiac disease (heart failure and/or coronary artery disease). Second, the decrease of the diastolic blood pressure leads to the increase of pulse pressure and the increment in pulse pressure may be responsible for the "J"-like relation (Berl and Henrich 2006). 
The ill effects of hypertension are usually attributed to the reduction in the internal diameter of arterioles, resulting in a peripheral resistance increase. Blood pressure is the easiest measurable index of opposition to left ventricular ejection (afterload). In fact, the appropriate term to define the arterial factors opposing LV ejection is the aortic impedance, which depends on: 1) the peripheral resistance, 2) the viscoelastic properties of the aorta and central arteries, and 3) the inertial forces represented by the mass of the blood in the aorta and left ventricle (Nichols and O'Rourke 2005). Peripheral resistance, as a determinant of mean blood pressure, sets the general level at which the pressure wave will fluctuate. The amplitude of this fluctuation (pulse pressure) is influenced by the viscoelastic properties of the aorta and large arteries and by the characteristics of the left ventricular ejection (stroke volume and ejection velocity). The viscoelastic properties of the aorta can be described in terms of compliance, distensibility and stiffness (Meeus et al. 2000). Stiffening of arterial walls can increase the afterload independently of peripheral resistance. Clinically, high aortic stiffness is suspected in patients with high pulse pressure. The latter can occur in case of diastolic pressure decrease, systolic pressure increase, or both. Arterial stiffening leads to faster pulse wave velocity, which, after the reflections at the level of the peripheral arteries, returns earlier to the aorta, amplifies aortic and even ventricular pressures during systole (aortic valve is still open) and reduces aortic pressure during diastole (Safar et al.1990). Vitious circle continues by further stiffening of arteries. Arterial stiffening is also a result of metabolic disturbances (see below).

\section{Vascular pathology, coronary artery disease}

Several vascular pathologies play a role in patients suffering from ESRD. These include 1) atherosclerosis, 2) arteriosclerosis, and 3) vascular calcifications and remodeling.

Atherosclerosis develops rapidly in ESRD patients. Uremia produces specific atherogenic factors, e.g. secondary form of complex dyslipidemia (Madore 2003), calcium-phosphate metabolism alterations (Floege and Ketteler 2004), malnutrition, and activation of inflammation (Madore 2003). These factors are additive to the risk factors present in patients with normal renal function, such as age, hypertension, smoking, diabetes, male gender and insulin resistance (Brunner et al. 2005). Although atherosclerosis was considered the only cause of macrovascular disease, many vascular complications arise in ESRD patients in the absence of clinically significant atherosclerotic disease.

Arteriosclerosis refers to the hardening or stiffening of arteries (or arterioles). It is typically associated with aging and involves the entire arterial tree, although it principally affects the elastic arteries. Unlike atherosclerosis, arteriosclerosis involves both intimal and medial thickening. Arteriosclerosis is associated with vascular hypertrophy characterized by increased wall thickness, lumen enlargement, and increased length of arteries, referred together as remodeling (London 2003a,b).

Histologically, arteries from uremic patients have been reported to have fibrous or fibroelastic intimal thickening; calcification of the internal elastic lamella, medial ground substance and medial elastic fibers; and disruption and reduplication of the internal elastic lamella (Ibels et al. 1979). These indicate the predominance of arterial calcification in uremia and provide histological evidence for the loss of elasticity in ESRD. Excessive calcification also affects the cardiac valves.

Tunica media calcification is a common feature in ESRD subjects. Diabetes mellitus is the strongest risk factor, but uremia per se has also been shown to contribute. It is due to disturbed calcium/phosphate metabolism - abnormal phosphate homeostasis in the setting of ESRD markedly alters the severity, progression, and extent of vascular calcifications (Vattikuti et al. 2004). Vitamin D deficiency, as a result of kidney failure, affects cardiac contractility, vascular tone, cardiac collagen content and cardiac tissue maturation (Achinger and Ayus 2005). Reduced levels of vitamin D, hyperphosphatemia and a tendency towards hypocalcemia lead to the increased production of parathormone and the secondary hyperparathyreoidism develops (DeFrancisco 2004). Clinically, so-called calcium/phosphate product is used as a measure of calcium/phosphate metabolism. Detailed description of the mechanisms of vascular calcifications is behind the scope of this review. Higher concentrations of aldosterone, endothelin, angiotensin II or asymetric dimethylarginine (ADMA, which is an endogenous inhibitor of nitric oxide synthase) also contribute to higher arterial stiffness.

\section{Valvular disease}

Valvular calcifications are typical for ESRD patients. They mostly occur in mitral and aortic valve and 
are markers of poorer prognosis. Wang et al. (2003) found that valvular calcification is an important predictor of all-cause and cardiovascular mortality in peritoneal dialysis patients. They hypothesized, that the poor outcome could be explained by the fact that these patients have the most severe and advanced atherosclerosis. On the contrary, the increased mortality was not explained by the valvular obstruction. Despite the findings of Wang et $a l$. , the incidence of aortic valve stenosis increases during last two decades (Michel 1998). It is explained by increasing age of hemodialyzed population, but the disturbances of calcium/phosphate metabolism probably also play a role together with the increased shear of aortic valve due to hyperkinetic circulation. In a general population, aortic stenosis leads to heart failure in its late stage. In ESRD patients, aortic stenosis could contribute to heart failure symptoms earlier.

Mitral valve calcifications lead only rarely to the development of significant regurgitation/stenosis. Valvular regurgitation may be also a result of infective endocarditis. It is more common in patients dialyzed via permanent catheter (Kamalakannan et al. 2007).

\section{Vascular access}

Surgically created vascular access, either "native" (direct connection of patient's artery and vein) or with the use of artificial graft, serves for repeated entries into the blood stream during hemodialyses. Adequate flow volume is needed for the hemodialysis procedure and also for longer patency of the access. Generally, forearm accesses have flow 400-800 $\mathrm{ml} / \mathrm{min}$, brachial accesses $800-1500 \mathrm{ml} / \mathrm{min}$. Such flow is due to a sudden fall of peripheral vascular resistance just after the access creation together with further maturation of both the feeding artery and outflow vein. This systemic vascular resistance decrease leads to subsequent volume overload and - at least temporarily - to increased cardiac output and left ventricle ejection fraction (Ori et al. 1996). Bos et al. (1999) studied the effects of vascular access on cardiac oxygen supply and demand using pressure wave analysis. They concluded that access has small effect on left ventricular oxygen demand, but decreases cardiac oxygen supply considerably.

Case reports of hyperkinetic heart failure as a result of high flow access have been published (Jin et al. 2006). More commonly, access flow contributes to the development of already present congestive heart failure either clinically silent or overt. Such opinion is supported by the following studies of access creation impact on heart failure parameters. Ori et al. (1996) documented an increase of cardiac output, ejection fraction, cardiac index and of atrial natriuretic peptide and a decrease of plasma renin activity in a small study (10 subjects). Similar findings were observed two weeks after access creation (Iwashima et al. 2002), and left ventricle diastolic function worsened after access creation together with the increase of ANP and BNP. We observed a significant increase of BNP levels six weeks after the construction of vascular access with "normal" flow $(709 \pm 311 \mathrm{ml} / \mathrm{min})$ (unpublished data). Unfortunately, these studies do not demonstrate the long-term effect of access flow on heart failure.

An opposite approach was used by Chemla et al. (2007) they monitored the effect of surgical access flow reduction on cardiac output in a group of high access flow patients $(3135 \pm 692 \mathrm{ml} / \mathrm{min})$. Access age (mean \pm SD) at inclusion was $30 \pm 17$ months and only accesses with flow volume exceeding $1600 \mathrm{ml} / \mathrm{min}$ were included. Cardiac output decreased significantly after the surgery together with the access flow. Similar topic (but with the use of a different flow-reducing surgical technique) was studied in a case reported by Murray et al. (2004). The most interesting finding in this study was that in highoutput states (induced by high flow accesses), the necessary increase in cardiac output to sustain the high access flows must be numerically greater than the actual access flow. This phenomenon was also apparent in the study by Chemla et al. (2007) where access flow reduction of about $2 \mathrm{l} / \mathrm{min}$ led to cardiac output decrease by more than $3 \mathrm{l} / \mathrm{min}$. We could hypothesize that this numerical imbalance mirrors excessive increase of preload or, in other words, a sign of heart failure.

\section{Other mechanisms}

Hemodialysis is associated with repetitive hemodynamic instability and subsequent myocardial ischemia, which may be due to coronary microvascular dysfunction. This process may also be important for the development of heart failure in hemodialysis patients (McIntare et al. 2008).

Pericardial effusions are common in ESRD patients, but only rarely significant if chronic dialysis therapy has been established. Various arrhythmias could be present as a result of ionic imbalance. They could contribute to the CHF by impaired left ventricular filling. Sleep apnea is common in ESRD patients (Kimmel et al. 1989) and leads to nocturnal hypoxemia. Malnutrition is also common and is associated with higher risk of CHF 
(Foley et al. 1996b). It could be estimated by the level of serum albumin.

Kidney transplantation leads (sometimes) to the regression of the left ventricular hypertrophy and systolic dysfunction (Parfrey et al. 1995). This phenomenon was explained by the decrease of "uremic toxin" levels and the term "uremic cardiomyopathy" is sometimes used to describe the complex non-coronary left ventricular changes in ESRD patients (Gross and Ritz 2008). However, patients treated by hemodialysis do not have real clinical signs of uremia and many so called "uremic toxins" were already discovered - aldosterone, endothelin, angiotensin II, ADMA, parathormone, cytokines, advanced glycation end-products, advanced oxidation protein products, etc. (for review see also Cibulka and Racek 2007).

\section{Research and diagnostic limitations}

The research, but also the clinical care, is limited especially by the fact that the steady state of CHF in ESRD patients does not exist. Volume load changes between dialyses could be documented by changing blood pressure, heart rate, vascular access flow, left ventricle diameter and mass (Paleček et al. 2008), by levels of natriuretic peptides etc. It is generally accepted that regular examinations should be performed at least $24 \mathrm{~h}$ after last hemodialysis, some authors examine just before the next dialysis.

\section{Conclusions}

Congestive heart failure is common in ESRD patients and is associated with substantial morbidity and mortality. It is a result of a complex of mechanisms, some of them occurring solely in ESRD patients. Unfortunately, chronic hemodialysis therapy cannot fully replace functioning kidneys. Detailed understanding of the mechanisms leading to $\mathrm{CHF}$ could improve the outcome of ESRD.

\section{Conflict of Interest}

There is no conflict of interest.

\section{Acknowledgements}

Authors thank for the support by the grant NS10590-3 of the Internal Grant Agency, Ministry of Health, Czech Republic.

\section{References}

ACHINGER SG, AYUS JC: The role of vitamin D in left ventricular hypertrophy and cardiac function. Kidney Int Suppl 95: S37-S42, 2005.

AMANN K, BREITBACH M, RITZ E, MALL G: Myocyte/capillary mismatch in the heart of uremic patients. $J$ Am Soc Nephrol 9: 1018-1022, 1998.

BAKRIS GL, WILLIAMS M, DWORKIN L, ELLIOT WJ, EPSTEIN M, TOTO R, TUTTLE K, DOUGLAS J, HSUEH W, SOWERS J: Preserving renal function in adults with hypertension and diabetes: a consensus approach. National Kidney Foundation Hypertension and Diabetes Executive Committees Working Group. Am J Kidney Dis 36: 646-661, 2000.

BERL T, HENRICH W: Kidney-heart interactions: epidemiology, pathogenesis, and treatment. Clin J Am Soc Nephrol 1: 8-18, 2006.

BOS WJW, ZIETSE R, WESSELING KH, WESTERHOF N: Effect of arteriovenous fistulas on cardiac oxygen supply and demand. Kidney Int 55: 2049-2053, 1999.

BOUTITIE F, GUEYFFUER F, POCOCK S, FAGARD R, BOISSEL P for the INDIANA project steering committee: J-shaped relationship between blood pressure and mortality in hypertensive patients: new insights from a metaanalysis of individual-patient data. Ann Intern Med 136: 438-448, 2002.

BRUNNER H, COCKCROFT JR, DEANFIELD J, DONALD A, FERRANNINI E, HALCOX J, KIOWSKI W, LÜSCHER TF, MANCIA G, NATALI A, OLIVER JJ, PESSINA AC, RIZZONI D, ROSSI GP, SALVETTI A, SPIEKER LE, TADDEI S, WEBB DJ: Endothelial function and dysfunction. Part II: Association with cardiovascular risk factors and diseases. A statement by the Working Group on Endothelins and Endothelial Factors of the European Society of Hypertension. J Hypertens 23: 233-246, 2005.

CHAIGNON M, CHEN WT, TARAZI RC, BRAVO EL, NAKAMOTO S: Effect of hemodialysis on blood volume distribution and cardiac output. Hypertension 3: 327-332, 1981. 
CHARRA B: Fluid balance, dry weight, and blood pressure in dialysis. Hemodial Int 11: 21-31, 2007.

CHEMLA ES, MORSY M, ANDERSON L, WHITEMORE A: Inflow reduction by distalization of anastomosis treats efficiently high-inflow high-cardiac output vascular access for hemodialysis. Semin Dial 20: 68-72, 2007.

CIBULKA R, RACEK J: Metabolic disorders in patients with chronic kidney failure. Physiol Res 56: 697-705, 2007.

COLLINS AJ: Cardiovascular mortality in end-stage renal disease. Am J Med Sci 325: 163-167, 2003.

DE FRANCISCO ALM: Secondary hyperparathyreosis: review of the disease and its treatment. Clin Ther 26: 19761993, 2004.

DRUEKE TB, LOCATELLI F, CLYNE N, ECKARDT KU, MACDOUGALL IC, TSAKIRIS D, BURGER HU, SCHERHAG A; CREATE Investigators: Normalization of hemoglobin level in patients with chronic kidney disease and anemia. N Engl J Med 355: 2071-2084, 2006.

FAGUGLI RM, REBOLDI G, QUINTALIANI G, PASINI P, CIAO G, CICCONI B, PASTICCI F, KAUFMAN JM, BUONCRISTIANI U: Short daily hemodialysis: blood pressure control and left ventricular mass reduction in hypertensive hemodialysis patients. Am J Kidney Dis 38: 371-376, 2001.

FELLNER SK, LANG RM, NEUMANN A, KORCARZ C, BOROW KM: Cardiovascular consequences of correction of the anemia of renal failure with erythropoietin. Kidney Int 44: 1309-1315, 1993.

FLOEGE J, KETTELER M: Vascular calcification in patients with end-stage renal disease. Nephrol Dial Transplant 19 (Suppl 5): V59-V66, 2004.

FOLEY RN, PARFREY PS, HARNETT JD, KENT GM, MARTIN CJ, MURRAY DC, BARRE PE: Clinical and echocardiographic disease in patients starting end-stage renal disease therapy. Kidney Int 47: 186-192, 1995.

FOLEY RN, PARFREY PS, HARNETT JD, KENT GM, MURRAY DC, BARRE PE: The impact of anemia on cardiomyopathy, morbidity, and mortality in end-stage renal disease. Am J Kidney Dis 28: 53-61, $1996 \mathrm{a}$.

FOLEY RN, PARFREY PS, HARNETT JD, KENT GM, MURRAY DC, BARRE PE: Hypoalbuminemia, cardiac morbidity, and mortality in end-stage renal disease. J Am Soc Nephrol 7: 728-736, $1996 \mathrm{~b}$.

GROSS ML, RITZ E: Hypertrophy and fibrosis in the cardiomyopathy of uremia - beyond coronary heart disease. Semin Dial 21:308-318, 2008.

HANSSON L, LINDHOLM LH, NISKANEN L, LANKE J, HEDNER T, NIKLASON A, LUOMANMAKI K, DAHLOF B, DEFAIRE U, MORLIN C, KARLBERG BE, WESTLER PO, BJORCK JE: Effect of angiotensin-converting-enzyme inhibition compared with conventional therapy on cardiovascular morbidity and mortality in hypertension: the Captopril Prevention Project (CAPPP) randomised trial. Lancet 353: 611616, 1999.

HARNETT JD, FOLEY RN, KENT GM, BARRE PE, MURRAY D, PARFREY PS: Congestive heart failure in dialysis patients: prevalence, incidence, prognosis and risk factors. Kidney Int 47: 884-890, 1995.

HARNETT JD, MURPHY B, COLLINGWOOD P, PURCHASE I, KENT G, PARFREY PS: The reliability and validity of echocardiographic measurements of left ventricular mass index in hemodialysis patients. Nephron 65: 212-214, 1993.

HERZOG CA, MA JZ, COLLIN AJ: Poor long-term survival after acute myocardial infarction among patients on longterm dialysis. N Engl J Med 339: 799-805, 1998.

IBELS LS, ALFREY AC, HUFFER WE, CRASWELL PW, ANDERSON JT, WEIL R: Arterial calcification and pathology in uremic patients undergoing dialysis. Am J Med 66: 790-796, 1979.

IWASHIMA Y, HORIO T, TAKAMI Y, INENAGA T, NISHIKIMI T, TAKISHITA S, KAWANO Y: Effects of the creation of arteriovenous fistula for hemodialysis on cardiac function and natriuretic peptide levels in CRF. Am J Kidney Dis 40: 974-982, 2002.

JIN H, AFONSO L, SINGH A, MIGDAL S, SPEARS JR: Case report: recurrent heart failure with preserved ejection fraction but markedly elevated BNP in a 51-year-old female on hemodialysis with oversized AV fistula. Int $J$ Cardiol 110: 429-430, 2006.

KAMALAKANNAN D, PAI RM, JOHNSON LB, GARDIN JM, SARAVOLATZ LD: Epidemiology and clinical outcomes of infective endocarditis in hemodialysis patients. Ann Thorac Surg 83: 2081-2086, 2007.

KIMMEL PL, MILLER G, MENDELSON WB: Sleep apnea syndrome in chronic renal dialysis patients. Am J Med 86: 308-314, 1989. 
LEVY D, GARRISON RJ, SAVAGE DD, KANNEL WB, CASTELLI WP: Prognostic implication of echocardiographically determined left ventricular mass in the Framingham Heart Study. $N$ Engl J Med 322: 1561-1566, 1990.

LONDON GM: Cardiovascular disease in chronic renal failure: pathophysiologic aspects. Semin Dial 16: 85-94, 2003a.

LONDON GM: Cardiovascular calcifications in uremic patients: clinical impact on cardiovascular function. $J$ Am Soc Nephrol 14 (Suppl 4): S305-S309, 2003 b.

LONDON GM, FABIANI F, MARCHAIS SJ, DE VERNEJOUL MC, GUERIN AP, SAFAR ME, METIVIER F, LLACH F: Uremic cardiomyopathy: an inadequate left ventricular hypertrophy. Kidney Int 31: 973-980, 1987.

LONDON GM, GUERIN AP, MARCHAIS SJ, PANNIER B, SAFAR ME, DAY M, METIVIER F: Cardiac and arterial interactions in end-stage renal disease. Kidney Int 50: 600-608, 1996.

MA JZ, EBBEN J, XIA H, COLLINS AJ: Hematocrit level and associated mortality in hemodialysis patients. $J$ Am Soc Nephrol 10: 610-619, 1999.

MADORE F: Uremia-related metabolic cardiac risk factors in chronic kidney disease. Semin Dial 16: 148-156, 2003.

MADORE F, LOWRIE EG, BRUGNARA C, LEW NL, LAZARUS JM, BRIDGES K, OWEN WF: Anemia in hemodialysis patients: Variables affecting this outcome predictor. J Am Soc Nephrol 8: 1921-1929, 1997.

MALÍK J, SVOBODOVÁ J, TUKA V, MOKREJŠOVÁ M, TESAŘ V: Dyslipidemia and anemia in chronically hemodialyzed patients. Prague Med Rep 108: 177-184, 2007.

MALL G, HUTHER W, SCHNEIDER J, LUNDIN P, RITZ E: Diffuse intramyocardial fibrosis in uraemic patients. Nephrol Dial Transplant 5: 39-44, 1990.

MCINTARE CW, BURTON JO, SELBY NM, LECCISOTTI L, KORSHEED S, BAKER CS, CAMICI PG: Hemodialysis-induced cardiac dysfunction is associated with an acute reduction in global and segmental myocardial blood flow. Clin J Am Soc Nephrol 3: 19-26, 2008.

MEEUS F, KOURILSKY O, GUERIN AP, GAUDRY C, MARCHAIS SJ, LONDON GM: Pathophysiology of cardiovascular disease in hemodialysis patients. Kidney Int 58 (Suppl 76): S140-S147, 1989.

MICHEL PL: Aortic stenosis in chronic renal failure patients treated by dialysis. Nephrol Dial Transplant 13 (Suppl 4): 44-48, 1998.

MOECKS J: Cardiovascular mortality in haemodialysis patients treated with epoietin beta - a retrospective study. Nephron 86: 455-462, 2000.

MULLER R, STEFFEN HM, BRUNNER R, SARIC J, POLLOK M, BALDAMUS CA, KAUFMANN W: Changes in alpha adrenergic system and increase in blood pressure with recombinant human erythropoietin (rHuEpo) therapy for renal anemia. Clin Invest Med 14: 614-622, 1991.

MURRAY BM, RAJCZAK S, HERMAN A, LEARY D: Effect of surgical banding of a high-flow fistula on access flow and cardiac output: intraoperative and long-term measurements. Am J Kidney Dis 44: 1090-1096, 2004.

NICHOLS WW, O'ROURKE MF: Vascular impedance. In: McDonald's Blood flow in Arteries: Theoretical, Experimental and Clinical Principles. W.W. NICHOLS, M.F. O'ROURKE (eds), Hodder Arnold Publisher, London, 2005, pp 83-96.

ODAR-CEDERLOF I, BJELLERUP P, WILLIAMS A, BLAGG CR, TWARDOWSKI Z, TING G, KJELLSTRAND CM: Daily dialyses decrease plasma levels of brain natriuretic peptide (BNP), a biomarker of left ventricular dysfunction. Hemodial Int 10: 394-398, 2006.

ORI Y, KORZETS A, KATZ M, PEREK Y, ZAHAVI I, GAFTER U: Haemodialysis arteriovenous access - a prospective haemodynamic evaluation. Nephrol Dial Transplant 11: 94-97, 1996.

PALEČEK T, SKALICKÁ L, LACHMANOVÁ J, TESAŘ V, LINHART A: Effect of preload reduction by hemodialysis on conventional and novel echocardiographic parameters of left ventricular structure and function. Echocardiography 25: 162-168, 2008.

PARFREY PS, HARNETT JD, BARRE PE: The natural history of myocardial disease in dialysis patients. $J$ Am Soc Nephrol 2: 2-12, 1991.

PARFREY PS, HARNETT JD, FOLEY RN, KENT GM, MURRAY DC, BARRE PE, GUTTMANN RD: Impact of renal transplantation on uremic cardiomyopathy. Transplantation 60: 908-914, 1995.

PHRAMMINTIKUL A, HAAS SJ, ELSIK M, KRUM H: Mortality and target haemoglobin concentrations in anaemic patients with chronic kidney disease treated with erythropoietin: a meta-analysis. Lancet 369: 381-388, 2007. 
RITZ E, DIKOW R, MORATH C, SCHWENGER V: Salt - a potential 'uremic toxin'? Blood Purif 24: 63-66, 2006.

SAFAR ME, LEVY BI, LAURENT S, LONDON GM: Hypertension and the arterial system: clinical and therapeutic aspects. J Hypertens 8 (Suppl 7): S113-S119, 1990.

SCHRIER RW, ESTACIO RO, ESLER A, MEHLER P: Effects of aggressive blood pressure control in normotensive type 2 diabetic patients on albuminuria, retinopathy ad strokes. Kidney Int 61: 1086-1097, 2002.

SILBERBERG JS, BARRE PE, PRICHARD S, SNIDERMAN AD: Impact of left ventricular hypertrophy on survival in end-stage renal disease. Kidney Int 36: 286-290, 1989.

SINGH AK, SZCZECH L, TANG KL, BARNHART H, SAPP S, WOLFSON M, REDDAN D; CHOIR INVESTIGATORS: Correction of anemia with epoietin alfa in chronic kidney disease. $N$ Engl J Med 355 : 2085-2098, 2006.

STACK AG, BLOEMBERGEN WE: A cross-sectional study of the prevalence and clinical correlates of congestive heart failure among incident US dialysis patients. Am J Kidney Dis 38: 992-1000, 2001.

TRESPALACIOS FC, TAYLOR AJ, AGODOA LY, BAKRIS GL, ABBOTT KC: Heart failure as a cause for hospitalization in chronic dialysis patients. Am J Kidney Dis 41: 1267-1277, 2003.

XIA H, EBBEN J, MA JZ, COLLINS AJ: Hematocrit levels and hospitalization risks in hemodialysis patients. $J A m$ Soc Nephrol 10: 1309-1316, 1999.

VATTIKUTI R, TOWLER DA: Osteogenic regulation of vascular calcification: an early perspective. Am J Physiol 286: E686-E696, 2004.

WANG AYM, WANG M, WOO J, WAI-KEI LAM C, KAM-TAO LI P, LUI SF, SANDERSON JE: Cardiac Valve calcification as an important predictor for all-cause mortality and cardiovascular mortality in long-term peritoneal dialysis patients: a prospective study. J Am Soc Nephrol 13: 159-168, 2003.

ZIPES DP, LIBBY P, BONOW RO, BRAUNWALD E: Braunwald's Heart Disease. Elsevier Saunders, Philadelphia, 2005.

ZOCCALI C, MALLAMACI F, BENEDETTO FA, TRIPEPI G, PARLONGO S, CATALIOTTI A, CUTRUPI S, GIACONE G, BELLANUOVA I, COTTINI E, MALATINO LS, CREED INVESTIGATORS: Cardiac natriuretic peptides are related to left ventricular mass and function and predict mortality in dialysis patients. J Am Soc Nephrol 12: 1508-1515, 2001. 